\title{
On the Moraic Weight Representation of Geminates in Taguinian Algerian Arabic
}

\author{
Meymouna Bourzeg (Corresponding author) \\ The University of Jordan \\ E-mail: bourezegmimi@gmail.com
}

Radwan S. Mahadin

Department of English Language and Literature, The University of Jordan

PO Box 11942, Amman, Jordan

Received: February 14, 2020

Accepted: February 27, 2020

Published: March 10, 2020

doi:10.5296/ijl.v12i2.16648

URL: https://doi.org/10.5296/ijl.v12i2.16648

\begin{abstract}
This study sheds light on the moraic representation of geminates in Taguinian Spoken Arabic (TSA), a dialect of Algerian Arabic. The examined data were primarily provided by the first researcher who is a native speaker of the variety under scrutiny. To increase data reliability, the spontaneous speech of five Taguinian native speakers was analyzed by means of note taking and tape recording. The researchers support geminates' moraicity in TSA by proffering three pieces of evidence, namely bimoraic word minimality condition, word stress, and long vowel shortening before geminates. A systematic analysis of the data via the use of optimality framework comes out with the following findings. First, the presence of CVG words demonstrates that geminates, in this variety, are underlyingly weight bearing since the minimal size of prosodic words is bimoraic. Second, the mechanism by which stress is attracted to CVG syllables proves that CVG syllables are heavy syllables wherein its second mora is carried by the geminate consonant. Third, the non-cooccurrence of long vowels and geminate consonants within the same syllable is another proof for the moraicity of geminates as trimoraic syllables are banned in TSA.
\end{abstract}

Keywords: Moraic theory, Algerian dialect, Geminate, Word minimality, Stress, Long vowel shortening 


\section{Introduction}

Though Geminate consonants are reported in many languages including Arabic, Bengali, Berber, Estonian, Finnish, Cypriot Greek, Hindi, Hungarian, Italian, Japanese, Malayalam, Pattani Malay, Persian, Saami, Swiss German and Turkish (Kubozono, 2017); their phonological representations are still obscure. In Arabic phonology, for instance, researchers' interest has been oriented towards the analysis of the acoustic and articulatory properties of geminates. Contrariwise, there has been a noticeable lack of works that tie the role of Arabic geminates to the controversial issue within phonological theory regarding geminate representation, where there are two main dialectical non-linear views: the prosodic length and the moraic weight representations (Davis \& Ragheb, 2014). Leben (1980) advanced the prosodic length modal wherein segments are represented autosegmentally and are linked to timing slots. This model represents geminate consonant as a single long phoneme which is associated with two slots on a prosodic tier; whereas, the singleton is linked to only one timing slot. Under this model, the length of segments is defined by the number of timing slots that segments are linked to in the skeletal tier (Benyagoub, 2017). The analysis of geminates through prosodic length analysis has been addressed in several works including McCarthy (1979), Tranel (1991), and Levin (1985) who utilized an X-tier instead of a CV tier. The length approach was heavily criticized as it fails in differentiating light CVC from heavy CVC syllables (Jouini, 2015). The moraic theory, on the other hand, is the most eminent and influential syllable theory (Hyman, 1985). The basic assumption of this model is that syllables are composed of a mora (or morae) which is a unit of phonological weight. It is described phonologically with the diacritic $(\mu)$. Within the scope of the moraic theory, multiple models were propounded. Hyman's model (1985), on the one hand, suggests that all segments are underlyingly moraic, but onsets on the surface structure lose their weight and become headed by the nucleic mora. Hayes's 1989 model, on the other hand, advocates the belief that there is no shared mora between the onset and the nucleus of the syllable. Both Hyman's (1985) and Hayes's models postulate that onsets are non-moraic; however, their views were challenged by Topintzi (2006) who licensed the possibility for onset moraicity. The advantage of the moraic approach is that it solves many problems encountered in the $\mathrm{CV}$ and $\mathrm{X}$-slot models, including the treatment of compensatory lengthening and reduplication process, via weight analysis (Jouini, 2015).

To understand the distinction between length analysis and moraic representation of geminate consonants, consider the different representations of the Arabic word [lammah] 'he hinted' displaying an intervocalic geminate. 

a) Length approach
b) Syllable tier
c) CV tier
d) Phoneme tier
e) Moraic approach
f) Syllable tier
g) Mora tier
h) Phoneme tier

/ lammah/
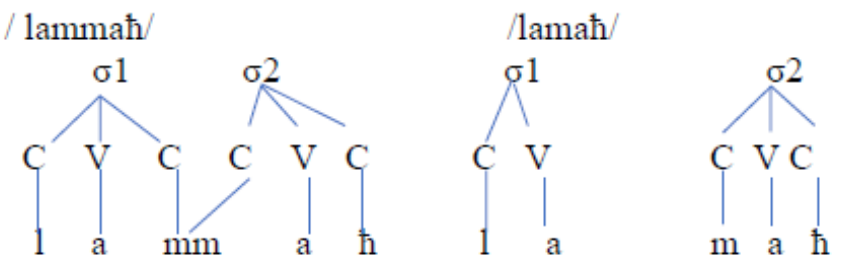

/ lamma

/amah/
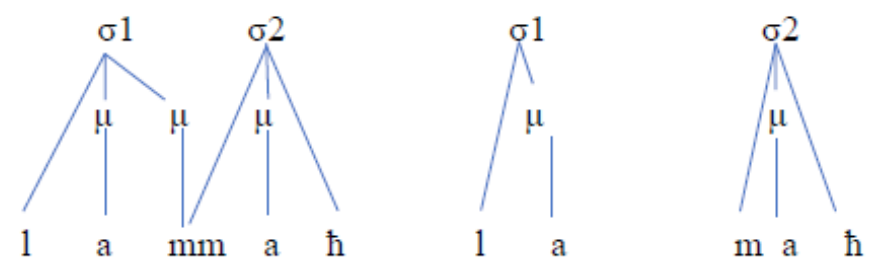

Figure 1. Representation of intervocalic geminate using (a) skeletal approach and (b) moraic approach

Within the moraic framework, short vowels and geminate consonants are underlyingly monomoraic, long vowels are bimoraic; whereas singletons are moraless segments (Davis \& Ragheb, 2014). According to this approach, syllables are differentiated in terms of heaviness. That is to say, a heavy syllable is bimoraic, whereas a light syllable is monomoraic. From figure1, it is noticed that the first syllable of the word / lammah/ is bimoraic whereas its second syllable is monomoraic. It is worth mentioning that the representation of geminate consonants could be analyzed through the framework of optimality theory which offers useful insights into input-output interactions.

The optimality theory was coined by the two linguists Alan Prince and Paul Smolensky in 1991 (McCarthy, 2002, p. 1). Usually, optimality theory is regarded as an extension of generative grammar. It has affected linguistic theory in general, but its impact on phonology was drastic. Unlike previous phonological theories that lean on rules to explain phonological realizations, optimality theory makes use of constraints. These constraints are universal and violable. Languages differ in their ranking of these constraints. Each of which has its own constraint ranking. It is the difference in ranking these constraints that leads to language variation (Prince\& Smolensky, 2004). The universal constraints are divvied into Markedness Constraints and Faithfulness Constraints. While Markedness Constraints ensure the wellformedness of the output candidates, Faithfulness Constraints necessitate the output forms to be identical to the input formats. The relation between the input and the output forms is intermediated by GEN and EVAL. The generator (GEN) constructs several possible candidates then the evaluator (EVAL) chooses an optimal candidate with reference to the specific ranking of constraints in a particular language. That is, the candidate that incurs the least violation of the high ranked constraints is chosen as the optimal candidate (Prince \& Smolensky, 1993/2004). Optimality theory utilizes tableaux to clarify how a particular candidate is chosen to be the optimal one. 
Table 1. The optimal output of /X/

\begin{tabular}{lll}
\hline$/ \mathrm{X} /$ & $\mathrm{A}$ & $\mathrm{B}$ \\
\hline $\mathrm{a}$. Candidate 1 & $!$ & \\
\hline b. Candidate 2 & & $*$ \\
\hline
\end{tabular}

$\mathrm{A} \gg \mathrm{B}$.

In Table 1. GEN creates two possible candidates: Candidate 1 and Candidate 2. Candidate 2 is the optimal output, the pointing hand ( $)$ denotes the optimal candidate because it satisfies the high ranked constraint A. Violations are marked by $\left(^{*}\right)$ while fatal violations are marked by (!). The diacritic (>>) is used to rank the constraints (Jouini, 2015).

\section{Literature Review}

Pieces of evidence vindicating the assumption that geminate consonants add weight to syllables could be scrutinized through a variety of phonological and morphological processes including, but not limited to, stress assignment, vowel lengthening, and reduplication (Tranel, 1991). It could be also explored by examining whether a language is subjected to word bimoraic minimality constraint, or it has compensatory lengthening process. Similarly, word-formation (Causative verbs, agent nouns, and instrument nouns) could give worthwhile intuitions on the representation of geminates (Noamane, 2019). Davis and Ragheb, (2014), on their turns, put forward multiple methods to verify how geminates are represented underlyingly; these methods include investigating the distinction between the patterning of geminates and consonant cluster. They have proved that in acquiring consonant clusters, children tend to delete the first consonant and geminate the final one to reserve the prosodic structure of the word. It is worth stating that the nature of evidence, used to investigate the patterning of geminates, differs from a language to another. In the Seto language, for instance, iambic feet must be trimoraic. This requirement is fulfilled through foot-final vowel lengthening. Consequently, a foot with the underlying structure CV.CVC surfaces as CV.CVVC; however, when the foot is of the form CV.CVG, no vowel lengthening takes place. Seto's avoidance of the foot CV.CVVG is a strong evidence for the moraic representation of geminates (Kiparsky, 2008). Quite similar to Seto, The West African language Fula bans CVVG syllables but licenses CVVC syllables. The Fulla language eschews trimoraic CVVG syllable through a degemination process (Paradis, 1988; Sherer, 1994).

Concerning the Arabic language, nearly every Arabic dialect is characterized by geminate consonants (Davis \& Ragheb, 2014). Some of these dialects exhibit strong support for the moraic analysis of geminates. For example, Moroccan Arabic provides solid arguments for the moraic patterning of geminates. In this dialect, content words are required to have at least binary feet. Consequently, words of the form CV are banned. However, it allows words of the form $\mathrm{GV}$ which result from the conflict between the following constraint IDENT-W > ${ }^{*} \mu / \mathrm{C}$, $* \mu / \mathrm{V}$. This situation is illuminated by the following data (1). 
(1) GV words in Moroccan Arabic (Noamane, 2019, p. 105)
1. ddi $* \mathrm{di}$
'to take'
2. $11 \mathrm{a}$ *la
'No'
3. $\mathrm{ssi}$
$*$ si
'Mr.'

Geminate consonants in Moroccan Arabic may also surface as a result of the application of compensatory lengthening which is a mora saving process. As a result of /a/ deletion from the feminine suffix/at/, the /t/ turns into a geminate consonant. Subsequently, geminates in Moroccan Arabic are said to be weight-bearing. The following items elucidate the point (2).

(2) Gemination by compensatory lengthening (Noamane, 2019, p. 117).

$\begin{array}{llll}\text { 1. } \text { dərbat } & \text { dərbət-u } & \text { dərbəttu } & \text { 'she hit him' } \\ \text { 2. } \text { Sərbat } & \text { Jərbət-u } & \text { Jərbəttu } & \text { 'she drank it' } \\ \text { 3. qətlat } & \text { qətlət-u } & \text { qətləttu } & \text { 'she killed him' }\end{array}$

In terms of optimality theory, the optimal candidate [ḍrbəttu] surfaces as a result of the conflict between the following constraints LINK- $\mu>*^{*}$ GEM. In addition to the Moroccan variety, Cairene Arabic presents persuasive arguments espousing the moraic nature of geminates. Syllables in Cairene Arabic cannot be stressed unless they are moraic; for that very constraint, the borrowed stressed English monosyllabic words into Cairene Arabic dialect undergo a process of geminating the last consonant to preserve the source language stress. The process by which geminates add weight to syllables is a strong piece of evidence for the weight nature of geminates. Data exhibiting this situation are introduced (3).

(3) Stress assignment in English borrowed words as used in Cairene Arabic (Davis \& Ragheb, 2014, p. 13).

\section{English}

1. (seven) up

2. book (purse)

3. watt
Cairene
Pabb
búkk
wá ț ț

Some languages exemplify problematic situations for the moraic theory such as the Selkup language, which is a west Serbian language. In this language, CVC structure is treated as a light syllable even if its final consonant is the first half of a geminate consonant. Furthermore, stress falls neither on CVC nor on CVG syllables (Tranel, 1991). Quite similar to Selkup, Tashlhiyt Berber seems to support the two C-slot analysis of geminates (Ridouanne, 2007). Geminates in the Austronesian language Leti may occur in a syllable-initial position which is a solid argument for the non-moraicity of geminates. By dint of being weight-bearing, geminates are barred from onset position since it is only the syllable rhyme that contributes to weight. Moreover; there is no coda in the onset position to host the first half of the geminates (Hume, Muller \& Engelenhoven, 1998). In Cypriot Greek, a process of nasal deletion across 
word boundaries occurs. In the CV framework, nasal deletion can be accounted for in a unitary manner. Within this framework, nasal deletion can be described as a process which is triggered by the consonant cluster that has a particular sonority ratio. That is, onset cluster and initial geminates form a natural class: each of which is linked to two $\mathrm{C}$ slots; however, within the moraic theory, onset cluster and initial geminates are represented differently. As a consequence of this representational difference, word onset clusters and geminates do not form a natural class. Thus, nasal deletion within the moraic theory cannot be explained in a unified manner (Muller, 2002). The Ngalakgan and Hungarian languages, too, offer challenging data for the moraic approach. Ngalakgan contradicts the basic assumptions of the moraic theory as geminates are moraless even if other codas are weight-bearing (Baker, 1997). In the Hungarian language, stress is attracted neither to final geminates nor to final consonant clusters. Furthermore, both final geminates and coda clusters trigger epenthesis. These two observations suggest that the phonological system of Hungarian language does not fit into the weight theory (Ringer \& Vago, 2011).

After reviewing the literature, it becomes crystal clear that geminate representation in Algerian spoken Arabic necessitates further studies since this issue was scrutinized previously neither through the optimality theory nor through any other phonological framework. Accordingly, the present paper aims at filling this gap by providing some pieces of evidence corroborating the moraic weight analysis of geminates in the Taguinian spoken variety of Algerian Arabic. Simultaneously, this paper would contribute to the ongoing debate in phonological theory regarding the representation of geminates in Arabic.

\section{Methodology}

The data of this study were mainly provided by the first researcher who is a native speaker of Taguinian spoken Arabic. To strengthen the validity of this paper, the researchers analyzed the spontaneous speech of five Taguinian native speakers by means of tape recording and note taking. Notably, in the present research social factor variables such as gender, age, education and the like are excluded.

\section{Results and Discussion}

In this section, pieces of evidence supporting the moraic weight representation of geminates are presented, elucidated and discussed. These pieces of evidence are stemmed from the bimoric word-minimality condition, word stress, and long vowel shortening before geminates.

\subsection{Evidence from Bimoric Word-Minimality Condition}

This section includes two parts. First, the bimoraicity of CCV and CV words is discussed to ensure that all words in the TSA dialect, with no exception, are subjected to word minimality condition. Then, the bimoraicity of CVG words is brought to the fore.

\subsubsection{Bimoraicity of CCV and CV Monosyllabic Words}

Many languages require their prosodic words to have at least one foot and prohibit degenerate foot meaning non-binary foot. Depending on the language, this requirement could be fulfilled 
either at the syllabic or moraic level. That is to say, the smallest size of a prosodic word should be either dissyllabic or bimoraic (Piggot, 2010). However, TSA has monosyllabic words (4) and (5).

(4) CV words
a. ma
'water'
f. mya
b. $\int \mathrm{a}$
'sheep'
g. nsa
h. Pța
I. nwa
d. $\mathrm{Bu}$
'father'
'come'
'brother'
j. șra
'hundred'
'he forgot'
'he gave'
'he intended'
'happened'

(5) CCV words

The above data, (4) and (5), eliminate the possibility that TSA words satisfy bimoraic foot binarity at the syllabic level. Now, an analysis of whether foot binarity, in TSA, could be preserved at the moraic level is needed. Under the moraic approach, word minimality condition is assured by MINPW which necessitates prosodic words to be at least bimoraic (Prince and Smolensky, 1993/2002). As an attempt to account for the bimoraicity of monosyllabic words, researchers such as Topintzi (2006) postulate that onset consonants are weight-bearing. Topintzi (2006) treats words consisting of CV and CCV structures as $(\mathrm{C} \mu \mathrm{V} \mu)$, $(\mathrm{C} \mu \mathrm{CV} \mu)$, respectively. However, the researchers at the present paper resolve the issue of $\mathrm{CCV}$ and $\mathrm{CV}$ bimoraicity without assigning a mora to onset consonants since the constraint barring moraic onsets is highly ranked in the variety under investigation. What is noticed, in TSA, is that long vowels appear when a suffix is added to CCV and CV syllables. The following data (6) clarify the situation.

(6)

$$
\begin{aligned}
& \text { ma:k } \\
& \text { Ja:k } \\
& \text { Xu:k } \\
& \text { mya:tak } \\
& \text { nsa:k } \\
& \text { Pța:k }
\end{aligned}
$$

$$
\begin{aligned}
& \text { 'your water' } \\
& \text { 'your sheep' } \\
& \text { 'your brother' } \\
& \text { 'your hundred' } \\
& \text { 'he forgot you' } \\
& \text { 'he gave you' }
\end{aligned}
$$

One way to account for the bimoraicity of CV and CCV syllables in TSA is to assume that their underlying forms are CVV and CCVV, respectively. These input forms surface as CV and $\mathrm{CCV}$ as a result of a constraint banning long vowels to surface in final positions. The mora carried by the long vowel exists to satisfy phonological rules but is not apparent in the word (Jouini, 2015, p. 462). An optimality analysis of bimoraic CCV words is realized via the subsequent three constraints. *ONSET $-\mu$ bans onsets from being moraic (Hayes, 1989). This constraint is highly ranked in TSA and eclipses PARSE- $\mu(\mathrm{V})$ which requires mora that are linked to a vowel underlyingly to be parsed into syllables (Prince \& Smolensky,1993). MAXPATH is the least ranked constraint in the proposed hierarchy. It ensures that paths 


\section{Macrothink}

International Journal of Linguistics

ISSN 1948-5425

2020, Vol. 12, No. 2

(association lines) which are presented in the input to be present in the output. The suggested constraint hierarchy together with Tableau 2 clarify how the bimoraicity of CCV words is assured.

Table 2. The optimal output for /șra/

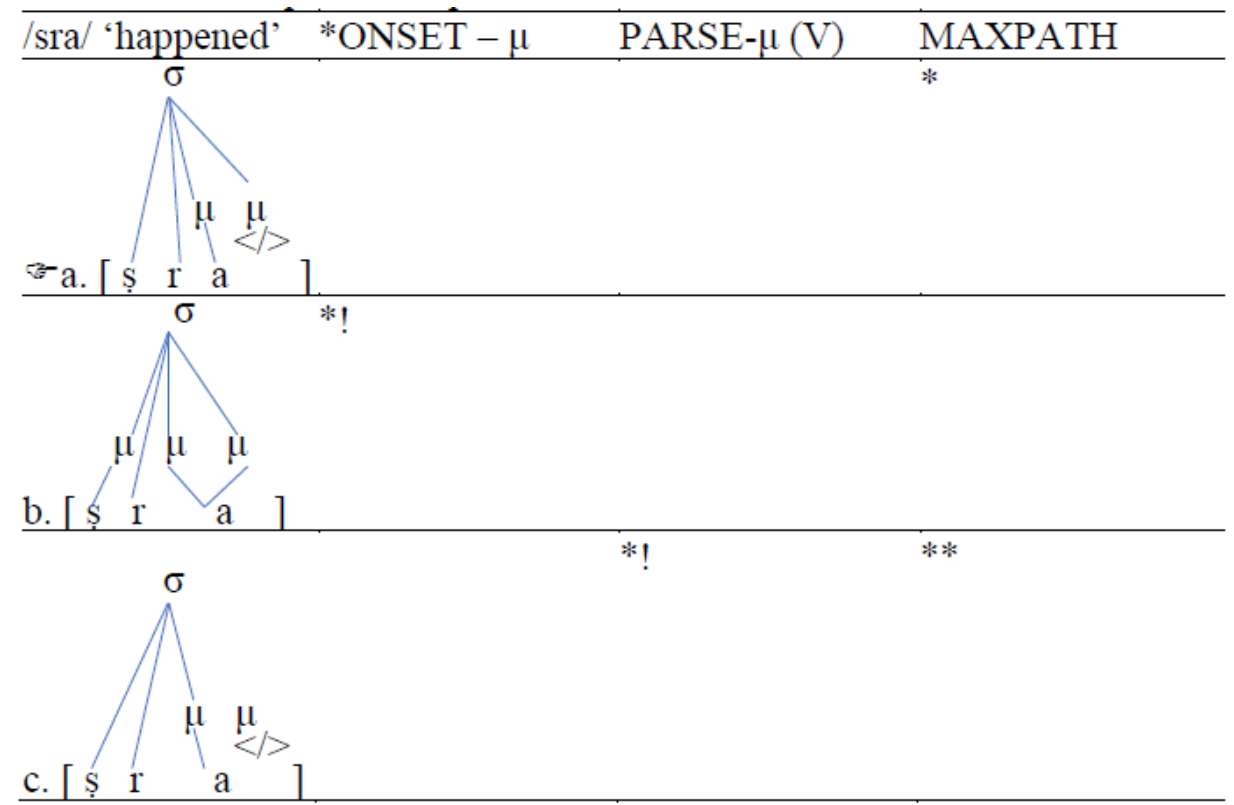

*ONSET $-\mu$ > PARSE- $\mu(\mathrm{V})>$ MAXPATH.

Candidate (a) is the optimal candidate which satisfies the high ranked constraints *ONSET -

$\mu$, PARSE- $\mu(\mathrm{V})$. The optimal candidate sustains satisfaction to *ONSET $-\mu$ and is faithful to the underlying vocalic mora. Though the second mora is present underlyingly, it fails to be realized in the output since it violates the low ranked constraint MAXPATH. Candidates (b) and (c) are ruled out as they incur fatal violations of *ONSET $-\mu$ and PARSE- $\mu(\mathrm{V})$ respectively. The bimoraicity of $\mathrm{CV}$ monosyllabic words is warranted by following the same line of reasoning.

\subsubsection{Bimoraicity of CVG Monosyllabic Words}

TSA dialect has CV and CCV monosyllabic words, yet it is characterized by the absence of CVC monosyllabic words. CVC word-candidates are ruled out because they incur fatal violation of the high ranked constraint *FINAL-C- $\mu$ which bans consonants in the final position from being moraic.

Table 3. The optimal output for/CVC/

\begin{tabular}{cll}
\hline$/ \mathrm{CVC} /$ & $*$ FINAL-C- $\mu$ & MINPW \\
\hline a. $[\mathrm{CV} \mu \mathrm{C}]$ & & $* !$ \\
\hline b. $[\mathrm{CV} \mu \mathrm{C} \mu]$ & $* !$ & \\
\hline
\end{tabular}

FINAL-C- $\mu$ > MINPW 


\section{Macrothink}

However, TSA allows words of the form CVG, as it is shown below (7).

(7)

$\begin{array}{ll}\text { Pumm } & \text { 'mother' } \\ \text { Yamm } & \text { 'uncle' } \\ \text { bazz } & \text { 'child' } \\ \text { Xadd } & \text { 'cheek' } \\ \text { terr } & \text { 'threaten' } \\ \text { dagg } & \text { 'knocking' } \\ \text { raqq } & \text { 'metal' } \\ \text { qatt } & \text { 'hot' }\end{array}$

What could be noticed so far is that unlike CVC constructions, CVG structures can form words on their own. Thus, CVG words satisfy word minimality condition. In terms of optimality theory, the bimoraicity of $(\mathrm{CV} \mu \mathrm{G} \mu)$ is instigated from the interaction between MINPW and the faithfulness constraint IDENT-IO (GEM) which requires each input geminate to have a correspondent output geminate (Abu-Abbas, Zuraiq \& Abdel-Ghafer, 2011). the constraint MINPW outranks IDENT-IO (GEM), since words in TSA are at least bimoraic. The suggested constraint ranking and tableau 4 illustrate the conflict between faithfulness and markedness constraints.

Table 4. The optimal output for /bazz/

\begin{tabular}{lll}
\hline /bazz/ 'child' & MINPW & IDENT-IO (GEM) \\
\hline a. [ $\quad \mathrm{b}$ & $* \mathrm{a}$ & \\
\hline & & \\
\hline
\end{tabular}

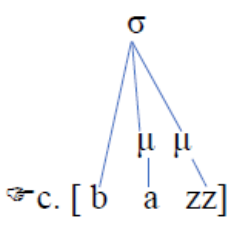

FT-BIN, *FINAL-C- $\mu$ > IDENT-IO (GEM) 


\section{Macrothink}

Candidate (b) does not satisfy the faithfulness constraint IDENT-IO (GEM). Violating the high ranked constraint MINPW leads to the elimination of candidate (a). Candidate (c) wins the competition as it satisfies all the suggested constraints.

\subsection{Word Stress and Geminate Consonants}

The syllable weight theory provides subtle analysis to stress assignment. Stress, under this approach, is attracted to heavy syllables to the exclusion of light ones (Al-Momani \& Mahadin, 2018). TSA displays a similar behavior. That is, the stress in this variety is sensitive to syllable weight. It could, for instance, falls on CVV syllables. Data exemplifying this situation are offered (8).

$\begin{array}{ll}\text { 'ma:kla } & \text { 'food' } \\ \text { 'Ja:tya } & \text { 'she wants' } \\ \text { 'Xa:tem } & \text { 'ring' } \\ \text { 'ṣa:ber } & \text { 'patient' }\end{array}$

Most importantly, it is noticed that stress in this variety is affected by the weight of the coda consonant. A coda consonant carries a mora that marks CVC syllable as heavy; however, if it is in word-final position the coda is extrametrical. This is what is known as the weight by position parameter (Hayes, 1989). The following instances (9) elucidate the distinction between heavy and light CVC syllables.
a. ma'dersa
'school'
b. ma'șelḥa
'broom'
c.' zamfa
'gathering'
d. 'saqsa
'he asked'
e. la'metna
'she gathered us'
f. 'za: me؟
'mosque'
g. 'na: Jef
'dry'
h. 'qawlab
'he deceives'
i. 'zaydet
'she gave birth'

Stress in (a-d) falls on penult CVC syllables. Hence, CVC syllable at this position is heavy. However, the stress in (f-i) falls on either penult CVV or penult CVC syllables to the exclusion of ultimate CVC. This is because final CVC is light syllables since *FINAL-C- $\mu$ bans final Coda from acquiring a mora. Stress in TSA also occurs on CVG syllables. Data displaying this situation are presented (10). 


\section{1) Macrothink}

International Journal of Linguistics

ISSN 1948-5425

2020, Vol. 12, No. 2

(10)

$$
\begin{aligned}
& \text { 'zawwazt } \\
& \text { 'tallaft } \\
& \text { 'Jammar } \\
& \text { 'șaffara } \\
& \text { ' } \text { arrabha } \\
& \text { 'haddara } \\
& \text { 'Sallam } \\
& \text { 'șabbar }
\end{aligned}
$$

\author{
'I got married' \\ 'I am lost' \\ 'he starts working with motivation' \\ 'whistle' \\ 'he made her drink something' \\ 'talkative' \\ 'to teach' \\ 'to cause to be patient'
}

As it is plainly exposed in (10), stress is attracted to syllables containing geminate consonants. The fact that CVG syllable behaves like non-final CVC and CVV in attracting stress ascertains that this syllable is heavy. While its first mora is vocalic, its second mora is carried by the geminate consonant. An optimality account of stress assignment to CVG syllables requires citing three constraints. Notably, weight to stress principle WSP which necessitates heavy syllables to be stressed (Liberman \& Prince, 1977). This constraint is high ranked in TSA, since stress cannot be attracted to light syllables. This constraint predominates the NON-FINALITY (NONFIN) which states that stress does not fall on the final syllable of the word (Prince \& Smolensky, 1993/2004). The low ranked constraint MAINRT is also utilized to clarify that stressed foot is aligned with the right edge of the word (McCarthy \& Prince 1993). The constraint hierarchy along with table 5 illustrate the mechanism through which the optimal output ('haddara) is selected.

Table 5. The optimal output for /haddara/

\begin{tabular}{llll}
\hline haddara/'talkative'WSP & NONFIN & MAINRT \\
\hline a.('haddara) & & & $* * !$ \\
\hline b.Had('dara) & $* !$ & $*$ & $*$ \\
\hline c.Had(da'ra) & $* !$ & $!$ & \\
\hline
\end{tabular}

\section{WSP $>>$ NONFIN > > MAINRT}

Table 5 suggests that candidates (b) and (c) are dismissed because they severely violate the high-ranking constraint WSP. Moreover, both of them incur violation of NONFIN. The optimal candidate out of this conflict is candidate (a) since it violates the least ranked constraint MAINRT.

\subsection{Long Vowel Shortening Before Geminates}

Long vowels and geminates consonants, in TSA, cannot co-exist in the same syllable. What is discerned in this dialect is that long vowels are reduced whenever they co-occur with a geminate consonant in the same syllable. The collected data (11) illustrate the point. 
(11) Imperative verbs in TA

Adjectives in TA

/lazz/

/ $\mathrm{add} /$

/ৎаðð/

/ṣadd/

/batt! /la:z/

$/ \int \mathrm{a}: \mathrm{d} /$

/५a: ð/

/ṣa:d/

/ba: t $/$
Gloss

'go away'

'hold'

'bite'

'look'

'beat'

Contrariwise, long vowels in syllables ending with final singletons are not shortened. Consider (12).

$\begin{array}{llll}\text { Verbs } & \text { Gloss } & \text { Adjectives } & \text { Gloss } \\ \text { /fa:d/ } & \text { 'holder' } & \text { /fa:di/ } & \text { 'crazy' } \\ \text { /qa:s/ } & \text { 'he threw' } & \text { /qa:si/ } & \text { 'rough' } \\ \text { /șa:b/ } & \text { 'he found' } & \text { /șa:ba/ } & \text { 'it was raining' }\end{array}$

Vowel shortening can be viewed as a way of avoiding trimoraic syllables. Hence, long vowel shortening before geminate consonants in TSA does support the moraic representation of geminates. In terms of optimality theory, this situation is described by bringing three constraints to the forepart. Basically, the already mentioned MINPW, and IDENT-IO (GEM). While MINPW dominates IDENT-IO (GEM), the latter is predominated by *TRIMOR which bans trimoraic syllables (Prince, 1990). The constraint ranking along with tableau 6 describe the preceding interaction.

Table 6. The output of / add/

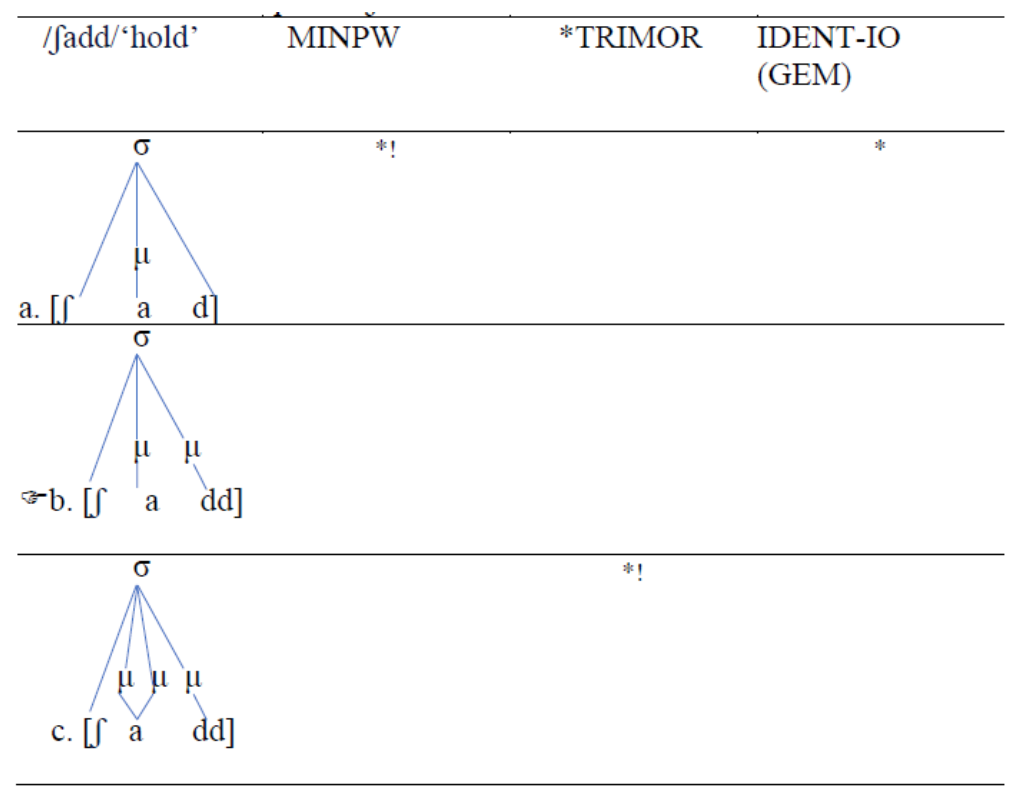

MINPW >>*TRIMOR >>*FINAL-C- $\mu>>$ IDENT-IO (GEM) 
Candidate (a) is ruled out for it sustains violation of the high ranked constraint MINPW which obliges prosodic words to be at least bimoraic. Candidate (c), on the other hand, is also dismissed since it severely breaks up *TRIMOR which bans trimoraic syllables. Consequently, candidate (b) is the optimal output as it satisfies both markedness and faithfulness constraints.

\section{Conclusion}

This study has scrutinized the representation of geminate in one of the Algerian dialects, TSA. Three pieces of evidence have been provided, exemplified and discussed via an optimality constraint-based approach for ratifying the moraicity of geminates in this variety; these pieces of evidence are emanated from word minimality condition, stress assignment, and long vowel shortening before geminates. The presented pieces of evidence highly fit into TSA's phonological system. First, it has been confirmed that the minimal size of prosodic words in TSA is bimoraic. Words of the structure CVG conforms to this bimoraicity condition suggesting that geminates are moraic. Second, stress in TSA is attracted towards heavy syllables including CVG ones. Similarly, this result approves that geminates are mora bearing segments. Finally, vowel shortening before geminate consonants as a result of *TRIMOR also supports the weight representation of geminates. Hopefully, future studies will provide additional distinct arguments supporting the weight analysis of geminates in Algerian Arabic. Furthermore, comparative studies between the weight analysis and the length analysis of geminates are highly needed in Algerian Arabic and Arabic phonology as a whole.

\section{References}

Al-Momani, D., \& Mahadin, R. S. (2018). Stress Patterns in Bani Saxar Arabic in Jordan: An Optimality Theory Perspective. The Jordanian Association for Educational Sciences, Jordanian Education Journal, 3(3), 48-72. Retrieved from http://jaes-jo.com/wp-content/uploads/2019/01/13-1.pdf

Baker, B. (1997). Edge Crispness: Segment to Mora Isomorphism. WCCF, (16), 33-47.

Benyagoub, L. (2017). A Moraically-Based Model of the Syllable in Bechar Arabic. Arabic Language, Literature \& Culture, 2(2), 40-48. https://doi.org/10.11648/j.allc.20170202.12

Davis, S., \& Ragheb, M. (2014). Geminate Representation in Arabic. Studies in Arabic Linguistics Perspectives on Arabic Linguistics, XXIV-XXV, 3-20. https://doi.org/10.1075/sal.1.04dav

Hayes, B. (1989). Compensatory Lengthening in Moraic Phonology. Linguistic Inquiry, 20(2), 253-306. Retrieved from https://pdfs.semanticscholar.org/34d4/9c900449022e3bc1c38aca4e2bb39c4f9769.pdf

Hume, E., Muller, J., \& Engelenhoven, A. V. (1998). Non Moraic Geminates in Leti.phonology, 14(3), 371-402. https://doi.org/10.1017/S0952675798003467

Hyman, 1. M. (1985). A Theory of Phonological Weight. Dordrecht: Foris. Retrieved from https://www.worldcat.org/title/theory-of-phonological-weight/oclc/13083980 
Jouini, M. (2015). On the Bimoraicity of Tunisian Arabic Open Monosyllables: A Moraic Optimality-Theoretic Approach. International Journal of Humanities and Cultural Studies, 2(3), 454-470.

Retrieved from https://pdfs.semanticscholar.org/2597/0bc75c7901cd8d2313b617b922963c7db533.pdf

Kiparsky, P. (2008). Weight and Length presented at City University of New York [CUNY]. Conference on the Syllable, New York City, January17-19.

Kubozono, H. (2017). The Phonetics and Phonology of Geminate Consonants (1st ed.). Oxford: Oxford University Press.

Leben, W. R. (1980). A Metrical Analysis of Length. Linguistic inquiry, 11, 497-509. Retrieved from www.jstor.org/stable/4178177

Levin, J. (1985). A Metrical Theory of Syllabicity. Ph. D. Dissertation, Massachusetts Institute of Technology, Cambridge, Massachusetts. Retrieved December 12, 2019, from https://dspace.mit.edu/handle/1721.1/1532

Liberman, M., \& Alan, P. (1977). On Stress and Linguistic Rhythm. Linguistic Inquiry, 8, 249-336. Retrieved from http://languagelog.ldc.upenn.edu/myl/LibermanPrince1977.pdf

McCarthy, J. J. (1979). Formal Problems in Semitic Phonology and Morphology. Ph. D. Dissertation, Massachusetts Institute of Technology, Cambridge, Massachusetts. https://doi.org/10.4324/9780429468629

McCarthy, J. J., \& Prince, A. (1993). Generalized Alignment. In G. Booij, \& J. Van Marle (Eds.), Yearbook of Morphology 1993. Yearbook of Morphology, Springer, Dordrecht. https://doi.org/10.1007/978-94-017-3712-8_4

McCarthy, J. J. (2002). A thematic guide to optimality theory. Cambridge: Cambridge University Press. https://doi.org/10.1017/CBO9780511613333

Muller, J. S. (2002). On the Theoretical Implications of Cypriot Greek Initial Geminates. Journal of Greek Linguistics, 3(1), 115-137. https://doi.org/10.1075/jgl.3.06mul

Noamane, A. (2019). The Moraic Nature of Geminate Consonants in Morrocan Arabic: Evidence from Word Minimality, Syllable Structure and Word Formation. International Journal of Arabic Linguistics, 5(2), 109-129. Retrieved from https://revues.imist.ma/index.php?journal=IJAL\&page=article\&op=view\&path $\% 5 \mathrm{~B} \% 5 \mathrm{D}=18$ 937\&path\%5B\%5D=10305

Paradis, C. (1988). On constraints and repair strategies. Linguistic Review, 6(1), 71-97. https://doi.org/10.1515/tlir.1987.6.1.71

Piggott, G. (2010). Cyclic Spell-out and The Typology of Word Minimality. Ms. McGill University, Montreal.

Prince, A. (1990). Quantitative Consequences of Rhythmic Organization, The Parasession on the Syllable in Phonetics and Phonology. Chicago Linguistic Society, 26, 355-398. 


\section{Macrothink}

International Journal of Linguistics

ISSN 1948-5425 2020, Vol. 12, No. 2

Prince, A., \& Smolensky, P. (1993). Optimality Theory: Constraint Interaction in Generative Grammar. Ms., Rutgers University, New Brunswick and University of Colorado, Boulder. Retrieved from http://roa.rutgers.edu/files/537-0802/537-0802-PRINCE-0-0.PDF

Prince, A., \& Smolensky, P. (1993/2004). Optimality theory: constraint interaction in generative grammar. Malden, MA: Blackwell. Retrieved from http://roa.rutgers.edu/files/537-0802/537-0802-PRINCE-0-0.PDF

Prince, A., \& Smolensky, P. (2004). Optimality Theory: Constraint Interaction in Generative Grammar. Malden: Blackwell Publishing. https://doi.org/10.1002/9780470756171.ch1

Ridouane, R. (2007). Gemination in Tashlhiyt Berber: An Acoustic and Articulatory study. Journal of the International Phonetic Association, 37(2), 119-142. Retrieved from www.jstor.org/stable/44526431

Ringen, C. O., \& Vago, R. M. (2011). Geminates: Heavy or Long?. Handbook of the Syllable. https://doi.org/10.1163/ej.9789004187405.i-464.47

Sherer, T. (1994). Prosodic phonotactics. Ph.D, Dissertation, University of Massachusetts, Amherst. Retrieved from http://roa.rutgers.edu/files/54-0395/54-0395-SHERER-1-0.PDF

Tranel, B. (1991). CVC Light Syllables, Geminates, and Moraic Theory. Phonology, 8(2), 291-302. Retrieved from www.jstor.org/stable/4420038

Topintzi, I. (2006). Moraic Onsets. Ph. D. Dissertation, University of London. Retrieved from https://discovery.ucl.ac.uk/id/eprint/1445127

\section{Copyrights}

Copyright for this article is retained by the author(s), with first publication rights granted to the journal.

This is an open-access article distributed under the terms and conditions of the Creative Commons Attribution license (http://creativecommons.org/licenses/by/4.0/) 